\title{
Субъекты квазипубличного взаимодействия в регионе ресурсного типа: взгляд изнутри ${ }^{1}$
}

\author{
С.Н. ЛЕВИН*, Е.А. КРАНЗЕЕВА**, К.С. САБЛИН ${ }^{* * *}$
}

\begin{abstract}
*Сергей Николаевич Левин - доктор экономических наук, профессор, кафедра экономической теории и государственного управления, Кемеровский государственный университет. Адрес: 650043, Кемерово, ул. Красная, д. 6. E-mail: levin.sergey.n@gmail.com

**Елена Анатольевна Кранзеева - кандидат социологических наук, доцент, заведующий кафедрой социологических наук, Кемеровский государственный университет. Адрес: 650043, Кемерово, ул. Красная, д. 6. E-mail: elkranzeeva@mail.ru

***Кирилл Сергеевич Саблин - кандидат экономических наук, доцент, кафедра экономической теории и государственного управления, Кемеровский государственный университет. Адрес: 650043, Кемерово, ул. Красная, д. 6. E-mail: sablin_ks@mail.ru
\end{abstract}

Цитирование: Левин С.Н., Кранзеева Е.А., Саблин К.С. (2021) Субъекты квазипубличного взаимодействия в регионе ресурсного типа: взгляд изнутри // Мир России. T. 30. № 4. C. 106-127. DOI: 10.17323/1811-038X-2021-30-4-106-127

В представленной статье на основе материалов глубинного интервью и анкетного опроса дана характеристика субъектов и практик политико-экономического взаимодействия в Кузбассе как в регионе ресурсного типа. В роли таких субъектов выступают представители региональной администрации и ресурсных компаний. Сравнительные преимущества представленного исследования заключаются именно во взгляде изнутри на данный региональный кейс, состоящчии в том, что исследователи сами были погружены в реалии экономики и общества Кемеровской области. Это означает, что они занимались решением специфической именно для сочиологии задачи теоретизации обыденного. Решение этой задачи предполагает использование исследовательской стратегии обоснованной теории, предполагающей выбор моделей и инструментов, соответствуюших особенностям объекта исследования.

Выбранная методология исследования позволила описать сложившиеся в Кузбассе практики квазипубличного взаимодействия, которые характеризуются следующчими чертами. Представители региональной власти и ресурсных компаний позиционируют

1 Статья опубликована в рамках проекта НИУ ВШЭ по поддержке публикаций авторов российских образовательных и научных организаций «Университетское партнерство». 
себя как субъекты, действуюшие в интересах всего населения региона. При этом они монополизируют функции формулирования и реализации общественных цуелей развития, заявляя о том, что только они обладают необходимой для этого информацичей и возможностями. В рамках такого подхода население практически исключается из числа активных субъектов политико-экономического и сочииального взаимодействия. В свою очередь представители властных структур и ресурсных компаний на неформальном уровне совместно реализуют как экономические, так и политико-административные функции. Власть привлекает предпринимателей к реализации своих политико-административных функций, включая финансирование производства общественных благ, различного рода социальных и инфраструктурных проектов и т. д. Предприниматели соглашаются на это, понимая, что без прямой поддержки власти ведение сколько-нибудь серьезного бизнеса невозможно. При этом все участники политико-экономического взаимодействия: политические руководители, профессиональные государственные служащчие, собственники и менеджеры ресурсных компаний - ведут себя не в соответствии со свочми формальными социальными ролями, а как персоны, включенные в закрытую вертикальную социиальную сеть.

Ключевые слова: регион ресурсного типа, квазипубличное взаимодействие, персонализация, органы власти, ресурсные компании, население, глубинное интервью

\section{Введение}

Представленное исследование ориентировано на комплексное рассмотрение двух самостоятельных, но в то же время пересекающихся проблем, которые имеют принципиальное значение для понимания содержания сложившейся в современной России конфигурации взаимосвязей между ресурсно-отраслевой структурой экономики и политико-экономической организацией общества.

Первая проблема связана с тем, что основу российской экономики и позиции в глобальной экономической системе образует экспортно-ресурсный сектор. Специфика его организации связана с формированием анклавов богатства. С одной стороны, эти анклавы ориентированы преимущественно на глобальные экономические рынки, не формируя длинных цепочек создания стоимости на территории страны. Однако, с другой стороны, централизация бюджетных и внебюджетных доходов от их деятельности обеспечивает выживание страны и реализацию политико-экономическими элитами своих интересов. В результате возникает сложное переплетение процессов экономической фрагментации и политико-административной централизации.

Второй проблемой является особенность политико-экономического взаимодействия, интегрирующего не только экономику, но и общество в России. Представляется, что попытка подогнать его под стандартные методологические схемы современных социальных наук: авторитаризма-демократии, централизации-децентрализации, унитаризма-федерализма - не позволяет раскрыть реальное содержание этого взаимодействия. Здесь мы сталкиваемся с ситуацией, о которой достаточно точно написал С.Г. Кордонский: «В области эмпирических знаний о стране уже много лет существует парадоксальная ситуация: с одной стороны, вся жизнь 
определялась и определяется постановлениями партии и правительства, указами президентов и другими нормативными актами. С другой стороны, мало какие из властных директив исполняются, и страна живет по-своему, часто вопреки официальной политике» [Кордонский 2008, с. 150]. В этой связи возникает вопрос о том, как соотносятся между собой формально заявленные и реальные практики политико-экономического и социального взаимодействия.

В условиях России наблюдается сложное переплетение публичности и приватности. С одной стороны, экономика и общество в нашей стране во многом огосударствлены, основные субъекты взаимодействуют в политической сфере. Это создает у предпринимателей мощную мотивацию к укреплению своего политического статуса, что, в частности, выражается в их широком представительстве в депутатском корпусе регионального и местного уровней [Сакаева 2012]. С другой стороны, это взаимодействие строится на персонализированных связях, максимально далеких от принципов публичной политики. Представители власти, бизнеса и организаций, формально представляющих гражданское общество, оказываются погруженными в сложные сети персонализированных связей, образующих систему квазипубличного взаимодействия. Это выражается в том, что декларируемый характер этого взаимодействия качественно отличается от его реального содержания. Примером такого разрыва формы и содержания выступает заявленное партнерство власти, бизнеса и организаций гражданского общества в реализации национальных проектов. Формально речь идет в явной или неявной форме об их взаимодействии в рамках публичной политики, что соответствует моделям тройной [Etzkowitz 1993; Etzkowitz, Leydesdorff 1995; Etzkowitz, Zhou 2018] и, особенно, четверной [Караяннис, Григорудис 2016; Carayannis, Campbell 2014; Höglund, Linton 2018] спиралей. Однако на практике данное взаимодействие базируется на системе персонализированных связей. По этой причине необходимо отметить принципиальное отличие персонализации от персонификации. В свое время Г.Б. Клейнер ввел в оборот модель экономики физических лиц [Клейнер 1996], в рамках которой речь идет о том, что собственники и руководители предприятий и организаций имеют целью не их развитие и в этом плане не являются их персонификацией, а используют их ресурсы для максимизации своих частных интересов как индивидуальных физических лиц (персон).

В ресурсных регионах в явной форме обнаруживается взаимосвязь между ресурсно-отраслевой структурой экономики и политико-экономической организацией общества. С одной стороны, в них сконцентрированы предприятия экспортно-ресурсного сектора, образующие производственную основу соответствующих анклавов богатства, с другой, в этих регионах сформировались устойчивые персонализированные практики квазипубличного взаимодействия. В этом плане сложившуюся в регионах ресурсного типа модель квазипубличного взаимодействия можно рассматривать как базовую для всей страны и в то же время как идеальную: в регионах ресурсного типа она проявляется в наиболее чистом виде. Исходя из последнего положения, особое значение приобретает взгляд изнутри самого региона.

Целью исследования является выделение субъектов, содержания и конфигурации квазипубличного взаимодействия в Кемеровской области, или Кузбассе, как типичном регионе ресурсного типа. 


\section{Методология исследования}

Специфика научной проблемы определяет выбор методологии исследования. Принципиальное значение для нас имеет трактовка современного общества как совокупности взаимосвязанных, но в то же время автономных систем: экономической, политической, социальной. Автономия экономики обеспечивается рынками со свободным конкурентным ценообразованием. Отличительной чертой современной России является формально заданная автономия этих сфер при их реальном переплетении на уровне внеформальных структур [Gel'man 2004; Ledeneva 2006; Torniainen, Saastamoinen 2007; Левин 2014].

Устойчивое несоответствие формальных институтов и реальных социальных практик отражает природу современного российского общества, которая качественно отличается от ситуации в странах с конкурентными экономическими рынками и политической демократией. В связи с этим значительный интерес представляют концепции этакратического общества О.И. Шкаратана [Шкаратан 2009; Шкаратан 2011] и сословного общества С.Г. Кордонского [Кордонский 2008; Кордонский 2010]. О.И. Шкаратан обращал внимание на то, что социально-экономическая система современной России - преемница советской квазисоциалистической, которую он содержательно определял как этакратическую. При этом неоэтакратическая система характеризуется тем, что «при доминировании не сошедшего со сцены этакратизма в России как бы на вторых ролях функционирует частнособственническая экономика с интенцией к формированию свободно-рыночного хозяйства» [Шкаратан, Ястребов 2008, с. 40]. Это означает, что преобладающая стратификация сословного типа в рамках вертикали власти может сосуществовать с гражданским взаимодействием, возникающим в рамках классового общества капиталистического типа. Развернутая характеристика сословной структуры постсоветского общества была дана в работах С.Г. Кордонского. В них он трактует современное российское общество не как классовое, базирующееся на механизмах свободного рынка, а как сословное, представляющее совокупность титульных и нетитульных (обслуживающих) сословий. «В сословно-государственном внерыночном единстве, не разделенном на классы, нет необходимости ни в демократии, ни в политике, т. к. согласование ресурсных интересов сословий осуществляется на административном рынке при административном торге по поводу «распила» ресурсов, консолидированных сувереном в общенародном - общесословном бюджете. Интересы такого государства в межгосударственных отношениях представляет суверен - президент или монарх» [Кордонский 2008, с. 126].

Значимость данных подходов заключается в том, что они демонстрируют социально-экономические основания устойчивого разрыва между закрепленными на уровне формальных институтов принципами равенства гражданской организации общества и возможностями взаимодействия его акторов в публичном поле, с одной стороны, и реалиями, характеризующими преобладание взаимоотношений сословного типа в рамках вертикали власти, с другой. В то же время, с нашей точки зрения, с опорой на конкретные кейсы необходимо раскрыть динамику этих взаимоотношений и переплетение различных начал, показать, что реальный тип взаимодействия характеризуется комбинацией неформальных и формальных установок. При этом особый интерес представляет то, как вертикаль власти контролирует 
бизнес и другие негосударственные субъекты, как последние могут реализовать свои интересы в публичном пространстве. Многие механизмы этих процессов раскрываются в рамках исследований С.Ю. Барсуковой, посвященных сращиванию теневой политики и теневой экономики [Barsukova 2019; Барсукова 2011; Барсукова 2006]: политико-экономические и социальные механизмы такого переплетения (сращивания) формируются и функционируют на микроуровне.

Для исследования на микроуровне используется междисциплинарный подход, построенный на интеграции социологических подходов с моделями и инструментами новой политической экономии (new political economy), а также современной политической науки [Congleton 2019; Persson, Tabellini 2000; Yakovlev 2006; Либман 2008]; принципиальное значение для нас имеют концептуальные подходы М. Олсона [Олсон 2012].

В предыдущих исследованиях авторами настоящей статьи был разработан и применен подход, построенный на выделении дискретных структурных альтернатив рынков власти: классического политического, административного, политико-административного [Левин 2012; Левин, Саблин 2018]. Сложившийся в России политико-административный рынок выступает ведущим механизмом не только политико-экономического, но и социального взаимодействия, поскольку в его рамках неразрывно переплетаются и переходят друг в друга политические, экономические и административные трансакции. В настоящее время фактически завершился процесс централизации данных трансакций, в результате чего резко возросла роль правителя и многократно, даже по сравнению с рубежом 1990-2000-х гг., снизились автономия и переговорные позиции двух других основных участников в лице руководителей территориальных (губернаторы) и производственных (олигархи) структур. Эти структуры представляют собой закрытые вертикально интегрированные социальные сети, при этом их руководители выступают не как классические рациональные бюрократы и шумпетерианские предприниматели, а как персональные хозяева - держатели индивидуального политического ресурса, конечным источником которого является правитель. Таким образом, в рамках сложившейся системы граница между представителями власти и бизнеса становится очень подвижна, причем и те и другие выполняют как экономические, так и политико-административные функции, неся при этом ответственность перед правителем.

Регион ресурсного типа в современной России с экономической точки зрения выступает как место базирования предприятий экспортно-ресурсного анклава богатства. Такой тип анклава определяется нами как классический, поскольку именно о нем идет речь в концепции анклавной двойственной экономики Дж. Стиглица [Stiglitz 2002]. Он отмечал, что соединение процессов либерализации и глобализации привело к формированию в странах с развивающимися рынками экспортно-ресурсных анклавов богатства, которые не оказывают скольконибудь значимого положительного влияния на модернизацию экономики данных стран, за исключением того, что они служат источником финансовых ресурсов для реализации государством различных проектов развития. В условиях России выделенные Дж. Стиглицем экспортно-ресурсные анклавы богатства формируются и функционируют в специфической форме:

1. Данные анклавы богатства контролируются не зарубежными транснациональными корпорациями (ТНК), а национальными государственными и аффилированными с государством частными компаниями и бизнес-группами [Паппэ, 
Галухина 2009]. Несмотря на размещение акций этих компаний на международных финансовых площадках и наличие среди них крупных зарубежных ТНК, их контрольные пакеты акций остаются в собственности либо российского государства ${ }^{2}$, либо частных интегрированных бизнес-групп [Паппэ 2002], контролируемых российскими физическими лицами (олигархами) ${ }^{3}$. Это непосредственно влияет на способы привлечения и использования ресурсов этих компаний для реализации проектов развития, инициированных государством.

2. Экспортно-ресурсные анклавы богатства встроены в специфическую систему, которая характеризуется сложным переплетением цепочек создания стоимости и ее перераспределения. Специфика этих отношений обусловлена тем, что формальные институты модифицируются неформальными нормами. В результате «белая» зона взаимодействия дополняется «черной» и «серой» при ведущей роли последней. Именно нормы «серой» зоны, определяющей набор квазифискальных обязательств бизнеса перед властью в форме квазиналоговых платежей и организованного спонсорства, устанавливают реальную финансовую нагрузку на эти компании [Левин, Курбатова 2011]. В то же время в ходе торгов в рамках «серой» зоны бизнес получает доступ к различным льготам и иным формам протекционистской поддержки, которая носит персонализированный характер.

В работах ряда политологов и социологов дается характеристика практик политического взаимодействия в регионах России. В.Я. Гельман показал структуру акторов политических процессов и их важнейшие параметры, выделил главные политические акторы - различные сегменты элиты; определил, что характер их взаимодействия играет важную роль в эволюции режима [Гельман, Рыженков 2000]. В 2011-2014 гг. А.Е. Чирикова и В.Г. Ледяев провели ряд исследований, в ходе которых были рассмотрены различные конфигурации власти в городах России. На основании проведенного анализа ученые пришли к выводу, что более значимыми и эффективными являются неформальные практики: они чаще всего и определяют характер взаимодействия между ключевыми акторами локальной политики, чем нормативные ресурсы [Чирикова, Ледяев 2017].

В унисон звучат работы известного исследователя региональных социальных и политических отношений А.В. Дуки, который приходит к выводу, что в настоящее время происходит частичная политизация региональной экономической элиты, связанная с вхождением персон в политическое пространство, при этом сохраняются основные позиции и интересы в экономическом пространстве. Это указывает на слабость гражданского общества и его возможности представлять интересы различных категорий населения в публичном пространстве [Дука 2019]. Он отмечает, что действие такого важного фактора, как формальный институциональный дизайн региональных законодательных структур, ограничивающий профессионализацию законодателей, ведет к социально-политической инволюции. Существенным аспектом данного процесса является деполитизация политической сферы, а объективным следствием такого развития становится превращение властных региональных структур и элит в новый нобилитет [Дука 2019, с. 169]. В то же время современная тенденция замещения губернаторов, укорененных в местных

\footnotetext{
2 ПАО «Газпром», ПАО «НК Роснефть», ПАО «НГК Славнефть».

3 Например, В.Ю. Алекперов и Л.А. Федун - ПАО «НК Лукойл»; А.А. Мордашов - ПАО «Северсталь»; В.С. Лисин - Группа НЛМК; А.И. Мельниченко - АО «СУЭК»; А.Г. Абрамов - Evraz Group.
} 
политико-экономических сообществах, порождает встречную тенденцию реполитизации местных элит. На примере исследования неформальных институтов организации избирательных кампаний эти проблемы рассматриваются в работе С.Ю. Барсуковой и С.Н. Левина [Барсукова, Левин 2020], где наряду с жесткой и мягкой моделями анализируется конфликтная модель. В рамках последней местные политико-экономические группы интересов организуют финансирование и продвижение к власти кандидатов в губернаторы и депутаты региональных законодательных собраний и органов местного самоуправления, альтернативных тем, которые предложены федеральным центром. Наиболее ярким кейсом выступила ситуация в Хабаровском крае.

\section{Эмпирическая база исследования}

Основным методом настоящего исследования выступает глубинное интервью. Выбор метода определяется трудностями в сборе надежных данных ввиду переизбытка разнородной статистической информации и отсутствия содержательных данных о характере реальных взаимодействий. Вся публичная информация СМИ носит лакированный характер пресс-релизов, отражающий лишь формальную сторону переговоров, встреч представителей угольных компаний, администрации и прочих. Сложность отбора информантов по заявленной проблеме состоит в том, что она не предполагает выявления массового мнения, характерного для анкетного опроса, в связи с чем мы использовали метод глубинного интервью с экспертами.

Модель выборки отражает логику решения исследовательской задачи, в которой необходимо было определить представления и практики участников публичного взаимодействия в регионе ресурсного типа - Кузбассе. Отбор информантов осуществлялся по сочетанию характеристик типичности и экспертности [Штейнберг 2014], которая предполагает наличие у информанта наиболее полных знаний о практике и в то же время его способность к рефлексии, возможность ее анализа и объяснения. Под типичностью мы подразумеваем, что ключевые информанты обладают типичными свойствами носителя практики, являются ее знатоками. Группа экспертов неоднородна, отличается глубиной рефлексии: одни из них опираются на свои знания о практике и результаты исследований; другие выстраивают рефлексию через осмысление практики, ее обобщение; третьи обладают глубокими знаниями в сфере своей практической деятельности.

В нашем исследовании представлены следующие типы экспертов:

- эксперт-теоретик (ЭТ); осмысляет проблему, может дать интересный комментарий, неожиданный взгляд на проблему с точки зрения своей сферы профессиональных интересов, связать с другими данными, расширить поле видения проблемы и т. п.; чаще экспертами в таком качестве выступали представители академических структур региона, изучающих социальные, экономические, технологические аспекты региональных проблем;

- ключевой эксперт (КЭ); является знатоком практики и рефлексирует, дополняя ее теоретическими выводами; эксперты этого типа обладают опытом работы в ресурсных компаниях, органах власти, в настоящее время занимаются исследовательской или преподавательской деятельностью; 
- типичный эксперт (ТЭ); знаток данной практики, который воспринимает ее как обыденную, не занимается ее теоретическим осмыслением; информантами здесь выступали представители высшего звена управляющих органов ресурсных компаний и властных структур.

Интервью проводились в рамках исследования «Формирование организационно-экономических механизмов комплексного освоения недр в регионах ресурсного типа», РНФ № 16-18-10182 (май-июнь 2017 г.), руководитель проекта - академик РАН А.Э. Конторович.

В статье также используются данные, полученные в рамках ежегодного мониторингового исследования «Кузбасс - политика», проводимого кафедрой социологических наук Кемеровского государственного университета. Мнение населения в исследовании отражено результатами анкетного опроса «Отношение населения к социальным проблемам региона и оценка состояния систем жизнеобеспечения» (апрель-июнь 2017 г.). Опрос проводился на территории Кемеровской области (Кемерово, Новокузнецк, Ленинск-Кузнецкий, Киселевск, Прокопьевск, Мариинск, Юрга и поселок городского типа Яя). Объем выборки - 1056 чел.

\section{Результаты исследования и обсуждение}

Проведенный анализ подтвердил квазипубличный характер взаимодействия в регионе ресурсного типа и позволил конкретизировать его основные характеристики применительно к Кузбассу. Логика эмпирического исследования была направлена на выявление характера политико-экономического взаимодействия. По форме такое взаимодействие является публичным, поскольку в сфере публичной политики происходит трансформация предпочтений представителей власти и ресурсных компаний в общественные цели. Публичное взаимодействие в своей идеальной модели имеет горизонтальный характер, означающий, что представители власти, бизнеса и структурированное в организации гражданского общества население совместно разрабатывают и согласовывают цели и инструменты социально-экономического развития территории. В ответах всех групп информантов присутствуют представления о том, что развитие должно происходить в интересах населения территории.

«Занятость приличная, безработииа уменьшается, но желательно, чтобы было больше (рабочих мест - прим. автора). Надо, конечно, давать рабочие места для людей, которые имеют физические и умственные способности, которые можно приложить» (муж., один из руководителей управления угольной промышленности по Кузбассу, профессор одного из технических университетов Кемеровской области, КЭ). «Бизнес в рамках законодательства ведет себя прилично. Это позволяет обеспечивать людей заработной платой, платить налоги своевременно, немалье, очень серьезные. Все это абсолютно чисто и прозрачно уже давным-давно, особенно в Кузбассе, это заслуга Кузбасса. Есть другие регионы, где немножко по-другому, но Кузбасс в этом плане на высоком уровне» (муж., заместитель генерального директора одной из ведущих ресурсных компаний Кузбасса, ТЭ). 
При этом возникает парадокс: информанты из числа представителей власти и ресурсных компаний не видят в населении реального партнера для взаимодействия, которое из субъекта выработки и реализации таких целей превращается в объект соуправления со стороны вышеуказанных субъектов. Говоря об интересах населения, они транслируют свои представления о нем, реализуя свои частные интересы, оставаясь узкими по составу группами специальных интересов. Население превращается в объект опеки, которому надо разъяснить, что нужно для развития региона и почему это в интересах самих жителей.

«На самом деле, как показал, в частности, город Прокопьевск, там полностью ушла моноотрасль. Хотя был город двести - почти триста тысяч, большой комплекс “Ленты”" построен, и торговые иеетры, и развлекательные чентры. Люди, конечно, ездят работать на шахты Киселевского района, в Новокузнецк, ну както растворились они. Город пока не умирает» (муж., руководитель регионального отделения одной из федеральных служб по техническому регулированию в сфере ТЭК, КЭ).

«Дальше с точки зрения среды, в которой проживают сотрудники и работники компании, в принципе все одинаковые, типовые все города. Я не видел большого различия, также строятся культурные и спортивные сооружения для того, чтобы была наполнена городская среда, чтобы люди там оставались. Чтобы было где отдохнуть, прийти с семьей, провести время, чтобы дети рождались, чтобы были детские сады, иколь и вся инфраструктура. <..> Все города одинаковые» (муж., заместитель генерального директора одной из ведущих ресурсных компаний Кузбасса, ТЭ).

Квазипубличность проявляется в том, что если на уровне формальных правил игры функции власти и бизнеса разграничены, то на неформальном уровне данные функции реализуются совместно при ведущей роли власти. Последняя привлекает предпринимателей к реализации своих политико-административных функций, включая финансирование производства общественных благ, различного рода социальных и инфраструктурных проектов, организацию проведения выборов и т. д. Предприниматели соглашаются на это, поскольку понимают, что без прямой поддержки властных структур ведение серьезного бизнеса невозможно.

«В этих соглашениях прописаны вопросы. <..> Мы инвестируем столько-то, мы отправили столько-то детей в пионерский лагерь, мы на такую-то сумму обеспечили безопасность, считается спецооежда и выдача другого (инвентаря - прим. автора). Бывают ситуации, когда серьезные организации (их просят - прим. автора): “Давай, помоги муниципалитету построить крытый стадиончик для хоккея”. При этом 50\% - они, 50\% - областной бюджет, это уже софинансирование» (муж., руководитель регионального отделения одной из федеральных служб по техническому регулированию в сфере ТЭК, КЭ). 
Помимо этого, в круг обязанностей предпринимателей включается участие в финансировании организации выборов в интересах вертикали власти. В результате возникает ситуация симбиотической связи представителей власти и бизнеса.

«Все абсолютно чисто и прозрачно, бизнес работает с властью во всех регионах, насколько я знаю, в очень тесном сотрудничестве. Поэтому сообщество бизнеса и власти нельзя разделять. Не может бизнес сам по себе без административных органов существовать» (муж., заместитель генерального директора одной из ведущих ресурсных компаний Кузбасса, ТЭ).

«Бизнес просто сам по себе? Ну не бывает бизнеса без власти. У нас соглашения есть с областью, безусловно. И везде идут взаимоотномения бизнеса и власти» (муж., заместитель генерального директора одной из ведущих ресурсных компаний Кузбасса, ТЭ).

С другой стороны, власть берет на себя предпринимательские функции, координируя деятельность бизнеса.

«Административный ресурс решает все. Раньше была организация, которая отстаивала права предпринимателей, а сейчас улаживают разногласия в администрации» (муж., руководитель регионального отделения одной из федеральных служб по техническому регулированию в сфере ТЭК, КЭ).

"Дело бизнеса - зарабатывать деньги. Издесь работает административный ресурс, плюс ко всему прочему наша администрация борется, чтобы снизить железнодорожные тарифы, потому что стоимость угля складывается не только из добытого угля; транспортировка стоит дороже, чем сам уголь» (муж., член различных экспертных советов при губернаторе Кемеровской области, занимающихся проблемами развития предпринимательства и конкуренции, ТЭ).

В свою очередь информанты, представляющие академическое сообщество, убеждены, что стержневым субъектом, устанавливающим правила взаимодействия, являются главы регионов.

«Вот если о регионе ресурсного типа говорить вообще, то можно сказать, что во многом зависит от позиции губернатора, от выстроенной структуры управления в регионе. <...> Собственно, регионы ресурсного типа везде сильных губернаторов имеют, наверное, так» (муж., специалист по вопросам стратегического управления в частном и публичном секторах, исследователь, ЭТ).

В данном случае информант подчеркивает факт персонализации отношений и их замыкание на фигуру губернатора. Переплетение проявляется в том, что представители власти реализуют свои административно-политические 
функции через взаимодействие с представителями ресурсных компаний, создавая систему, которую респонденты называют «принуждением к социальной ответственности».

\begin{abstract}
«Аман Гумирович с такими компаниями всегда правильно работает: "Давайтека повысим зарплату рабочим на 10\% на будущий год, построим детские сады, школь, спортивные сооружения". Это все, конечно, идет путем надавливания на богачей, и они вынуждены раскошелиться. Они высасывают из наших недр (ресурсы - прим. автора)» (муж., один из руководителей управления угольной промышленности по Кузбассу, профессор одного из технических университетов Кемеровской области, КЭ).
\end{abstract}

Информант при этом обращает внимание на то, что данная система персонализирована, ее параметры определялись установками А.Г. Тулеева, который всегда позиционировал себя в качестве хозяина Кузбасса. С другой стороны, представители ресурсных компаний четко демонстрируют понимание того, что реализация ими предпринимательских функций возможна только при административно-политической поддержке вертикали власти.

\begin{abstract}
«Я точно знаю, что те руководители, которые являются собственниками, выше менеджмента, с правительством постоянно тоже находятся в тесном сотрудничестве, в диалоге. Потому что это основные работодатели, налогоплательщики» (муж., заместитель генерального директора одной из ведущих ресурсных компаний Кузбасса, ТЭ).
\end{abstract}

Население воспринимается представителями вертикали власти и ресурсных компаний не как партнер, а как объект управления, при этом существует специфика отношения этих двух субъектов к жителям. Представители ресурсных компаний рассматривают население как еще один ресурс для своего развития, т. е. потенциальных и реальных работников.

«Есть профессиональное сообщество, которое работает профессионально на предприятиях, есть династии, которые работают много лет, с советских времен» (муж., заместитель генерального директора одной из ведущих ресурсных компаний Кузбасса, ТЭ)

При том, что работники - это необходимый ресурс для развития, остальное население не попадает в поле внимания власти и ресурсных компаний, кроме отдельных групп, которые несут определенную угрозу для развития бизнеса и воспринимаются как деструктивные элементы. 
«Есть сообщество тунеядцев или алкоголиков, как раз они и могут (предпринимать прим. автора) какие-то деструктивные шаги, но это везде, во всем мире. Есть такие люди, и все это абсолютно провокации» (муж., заместитель генерального директора одной из ведущих ресурсных компаний Кузбасса, ТЭ).

Информанты из числа представителей региональной власти рассматривают население с позиции выполнения своих показателей, от которых зависит отношение к ним со стороны вышестоящих властей (в современных условиях эти показатели оценки эффективности формализованы в рамках системы KPIs Key Performance Indicators). В этой связи региональные власти волнуют вопросы, связанные с тем, что в условиях слабо диверсифицированной экономики модернизация ресурсного сектора ведет к проблемам, провоцирующим социально-политическую нестабильность.

«Это нужно, как клапан, который будет сбрасывать сочиальное давление. В связи с модернизацией шахт и разрезов и введением новой техники количество рабочих мест уменьшается, хотя добыча увеличивается. Следовательно, надо развивать сочиальную инфраструктуру, другие отрасли промышленности, интеллектуальные и инновационные и прочие дела. Они не слишком у нас в Кузбассе будут (по контексту ясно, что информант видит ограничения в реализации инноваций, связанные с позицией региональной власти - прим. автора), потому что у нас администрация заинтересована в создании новых рабочих мест, но эти новые дела ориентированы на то, чтобы было поменьше народу и побольше выручки. Это психология, это как бы реальная действительность» (муж., член различных экспертных советов при губернаторе Кемеровской области, занимающихся проблемами развития предпринимательства и конкуренции, ТЭ).

Отношение к населению как к гражданам, имеющим собственные интересы и потребности, способным устанавливать границы социально-политического взаимодействия, и быть его участником, характерно для информантов - представителей академического сообщества.

«Население способно только установить какие-то общие рамочные границы, "требования” относительно условий и качества жизни, структуру рабочих мест, условий. “Качество жизни" - термин, который все определяет (муж., специалист по вопросам стратегического управления в частном и публичном секторах, исследователь, ЭТ).

Однако если информанты из числа представителей ресурсных компаний и органов власти описывают существующие практики, и в этом смысле данные описания носят позитивный характер, то рассуждения представителей академического сообщества носят преимущественно нормативный характер. При этом проблемой остается отсутствие рекомендаций со стороны академического сообщества относительно инструментов реализации предложенных нормативов. 
«Любой проект проходит экспертизу, в том числе экологическую и экономическую, бизнес-планы всякие. И когда смотришь на экономику, становится ясно: то ли здесь производить (технологии - прим. автора), то ли привести готовые. С точки зрения экономики, конечно, лучше и выгодно свое (производить - прим. автора), но оно должно быть конкурентоспособным. Вот в чем дело» (муж., специалист в области открытых угольных разработок, исследователь, ЭТ).

Следует отметить, что в рамках квазипубличного взаимодействия разного рода проекты и программы, разрабатываемые представителями из числа академического сообщества по заказу властей, выполняют специфическую функцию. Они не используются для трансформации существующих реальных практик. Фактически эти проекты и программы, с одной стороны, маскируют реальное содержание существующего квазипубличного взаимодействия, а с другой, ведут к появлению новых объектов административного торга и форм рентоориентированного поведения. В этой связи интересную оценку такой форме институциональной инновации, как внедрение специальных инвестиционных контрактов (СПИК), дает один из информантов, представляющих органы власти:

\begin{abstract}
«Вот что интересно - инвестичионные контракты. Но все должно быть прозрачно, а я вам так скажу: сегодня одна власть, а завтра другая власть. Эта власть подписывает, согласования должны пройти, а если власть поменялась и прокуратура - разберись там. Для инвестиционного контракта должна быть серьезно проработана нормативная база, прозрачная, чтобы здесь не было коррупционной составляющей, уже прямым текстом говорю» (муж., руководитель регионального отделения одной из федеральных служб по техническому регулированию в сфере ТЭК, КЭ).
\end{abstract}

По сути, данный информант обращает внимание на то, что любые формальные нормы встроены в систему персонализированного взаимодействия в рамках вертикали власти. Он настойчиво подчеркивает, что реальные практики взаимодействия зависят не от формальных правил, а от персоны руководителя - «сегодня одна власть, а завтра другая власть».

В связи с тем, что представители ключевых субъектов постоянно акцентируют, что действуют в интересах населения региона, значимым видится выявление представлений самих жителей об общественных интересах и целях социально-экономического развития региона. Проведенные нами фокус-группы этого периода демонстрируют запрос населения региона на справедливость, и в различных социальных группах она представлена в различных форматах. Сельские жители говорят об отсутствии внимания к проблемам «простых людей»; для учителей тема справедливости выглядит болезненной, они видят в ней политический подтекст и стараются избегать ее; очень остро воспринимают проблему справедливости шахтеры, считая себя ущемленными в профессиональном и социальном плане, обобщая, что справедливости нет [Кранзеева, Головаикий, Орлова, Бурмакина 2020]. 
Справедливость как социальное согласование в данном варианте предполагает обращение не к горизонтальным структурам взаимодействия - гражданскому обществу, а к действиям властей, работодателей в рамках вертикального взаимодействия. Это означает, что население действует в этой же логике квазипубличного взаимодействия, рассчитывая, что вышеуказанные субъекты сформулируют правильные цели общественного развития и будут реально работать в интересах населения. Жители региона готовы делегировать решение своих вопросов другим - репрезентантам [Кранзеева, Бурмакина, Алтемерова 2020]. Результаты анкетного опроса позволили выявить, что наиболее возможными представителями интересов являются правоохранительные органы (юристы, адвокаты - 16,4\%; прокуратура - 13,7\%, суд - 12,8\%), органы власти (президент - 6,2\%; губернатор - 5,4\%; органы местной власти - 3,5\%), социальное окружение (родные и близкие $-10,4 \%$; знакомые и социальные связи $-5,3 \%$; объединение с другими людьми - 3,9\%).

Мнение населения демонстрирует, что жители предъявляют высокий спрос на справедливость, но при этом не позиционируют себя в качестве активных граждан. Гражданская позиция предполагает использование стратегии «голос», но жители Кузбасса выбирают стратегии «лояльность» либо «выход» [Hirschman 1972]; последняя стратегия касается молодежи и представителей экономически активного населения, которые уезжают из региона. Невключенность населения в политико-экономическое взаимодействие в качестве относительного равноправного субъекта провоцирует ситуации, которые воспринимаются властью и бизнесом как угроза, поскольку нарушает их сложившуюся монополию на формулирование и реализацию целей развития региона.

Выбор частью жителей стратегии «голос» принимает в условиях квазипубличности форму вспышек протестной активности. В настоящее время эта угроза носит преимущественно локальный характер. Можно привести пример протестов экоактивистов в Черемзе (протест против строительства нового углепогрузочного комплекса в поселке в Новокузнецком районе Кемеровской области). Локальность этих протестов заключается в том, что они направлены не на изменение всей системы, а на решение конкретных проблем определенных узких групп интересов. Именно поэтому в настоящее время у представителей региональных властей есть возможность купирования этих угроз, что предполагает комбинирование использования административного ресурса с частичным учетом интересов протестующих. В качестве протестной трактуется практически любая гражданская активность, которая воспринимается властью и бизнесом не как приглашение к диалогу, а как противодействие согласованным ими целям развития. Поскольку квазипубличное взаимодействие, по сути, исключает гражданскую активность, то люди, нарушающие сложившиеся неформальные правила, воспринимаются как «бузотеры» ${ }^{4}$.

Другая угроза выражается в оттоке экономически активного населения, особенно молодежи, использующей стратегию «выход». Это серьезно затрагивает интересы как компаний ресурсного сектора, так и региональных властей.

4 Данное определение в публичном пространстве было использовано губернатором области А.Г. Тулеевым (Тулеев рассказал о митингующих в Кемерове «бузотерах» (2018) // Lenta.ru. 27 марта 2018 // https://lenta.ru/news/2018/03/27/buzoteri/, дата обращения 19.02.2021). 
Для первых это означает потерю человеческого капитала, а для вторых - ослабление их позиций в рамках вертикали власти. Данный факт получил признание на уровне официальных документов: примером может служить электронный бюллетень Правительства Кемеровской области - Кузбасса № 122 от 9 января 2019 г. «Об утверждении Стратегии социально-экономического развития Кемеровской области до 2035 года». В этом документе специально выделены следующие пункты:

- «снижение демографического потенциала: увеличение естественной убыли населения (с 2014 г.) и сокращение численности населения в муниципальных образованиях (особенно в муниципальных районах севера Кузбасса), не входящих в агломерацию Кемерово - Новокузнецк, в том числе за счет миграции в другие города и субъекты Российской Федерации»;

- «дисбаланс на рынке труда в результате сокращения численности трудоспособного населения вследствие высокой смертности данной возрастной группы, а также оттока квалифицированных кадров из региона» ${ }^{5}$.

Реакцией на это стало планирование в стратегиях и программах развития региона мер по предотвращению оттока населения и привлечения квалифицированных кадров: так, в последней «Стратегии социально-экономического развития Кемеровской области - Кузбасса на период до 2035 года», принятой в 2020 г., среди контуров приоритетов Стратегии первым назван «Кузбасс - регион достойной жизни людей», включающий следующие положения:

- «Кузбасс - центр профессионального превосходства»;

- «Кузбасс - центр высокого качества жизни населения»; «Кузбасс - центр достойного труда»;

- «Кузбасс - центр новых компетенций и рабочих мест зеленой экономики».

Однако опыт реализации ранее принятых проектов свидетельствует, что они носят преимущественно декларативный характер и не оказывают сколько-нибудь серьезного воздействия на сложившиеся тенденции развития.

В целом жители Кузбасса придерживаются стратегии «лояльность» и пока не превращаются в субъект, способный реально изменить общий характер сложившегося квазипубличного взаимодействия.

\section{Заключение}

Проведенный анализ выявил содержание и конфигурацию квазипубличного взаимодействия в Кузбассе. Сравнительные преимущества представленного исследования заключаются во взгляде изнутри на кейс Кузбасса как типичного региона ресурсного типа. Взгляд изнутри состоит в том, что как исследователи, так и исследуемые - информанты глубинного интервью и респонденты анкетного опроса - погружены в региональную экономику и общество. Сложившиеся практики напрямую влияют на все стороны их жизни, соответственно, исследователи

5 Электронный бюллетень Правительства Кемеровской области - Кузбасса № 122 от 9 января 2019 г. «Об утверждении Стратегии социально-экономического развития Кемеровской области до 2035 года» // /https://bulleten-kuzbass.ru/bulletin/210988\#_Тос531789883, дата обращения 04.02.2021. 
решали специфичную именно для социологии задачу теоретизации обыденного, используя при этом стратегию обоснованной теории, которая определяет применение набора моделей и инструментов, исходя из специфики объекта исследования. Это дало возможность избежать ситуации, когда заимствованные концепты и теории становятся преградой для научной характеристики реалий российского общества. При этом взгляд изнутри, безусловно, имеет свои ограничения. Плотная включенность исследователей в практики взаимодействия может ограничить их исследовательский кругозор, поскольку чрезмерная концентрация авторов на ситуации, в которую они сами погружены, может сужать круг исследуемых проблем и не позволяет в полной мере дать их сравнительную характеристику. Это означает, что такой подход не может замещать исследования, построенные на охвате обширного круга регионов и сравнительной характеристике сложившихся в них практик. Однако мы считаем, что он имеет свои сравнительные преимущества: данный подход позволил в ходе проведенного исследования представить достаточно развернутую характеристику квазипубличного взаимодействия в Кузбассе.

Политико-экономическое взаимодействие по форме является публичным, однако если в идеальной модели оно строится на горизонтальных связях власти, бизнеса и организаций гражданского общества, то в российских условиях оно реализуется в рамках вертикали власти, что превращает его в квазипубличное. Проведенное эмпирическое исследование позволило выделить следующие его характеристики, типичные для Кузбасса:

- представители власти и ресурсных компаний заявляют, что они действуют в интересах населения региона, однако при этом они, по сути, монополизируют функции формулирования и реализации общественных целей развития; соответственно, население из партнера превращается в объект соуправления с их стороны, который нужно убедить в том, что представители власти и ресурсных компаний лучше знают, что нужно населению;

- соуправление означает, что на неформальном уровне и власть, и бизнес совместно реализуют экономические и политико-административные функции; при этом предприниматели показывают, что без прямой поддержки власти ведение серьезного бизнеса невозможно, а власть привлекает предпринимателей к реализации своих политико-административных функций, включая финансирование производства общественных благ, различного рода социальных и инфраструктурных проектов и т. д.; такое соуправление может реализоваться только при том условии, что население придерживается стратегии «лояльность»; выбор представителями населения стратегии «выход» ведет к потере человеческого капитала; наиболее резкое неприятие вызывают попытки части граждан использовать стратегию «голос», при этом практически любая гражданская активность воспринимается как протестная; она рассматривается представителями власти и бизнеса не как приглашение к диалогу, а как нарушение их монополии на определение и реализацию целей развития;

- реализуя свои функции соуправления социально-экономическим развитием, политические руководители, профессиональные государственные служащие, собственники и менеджеры ресурсных компаний выступают не в соответствии со своими формальными социальными ролями, а как персоны, включенные в закрытую вертикальную социальную сеть; в рамках этой сети они выступают как 
хозяева территорий и организаций, и все вышесказанное означает устойчивую персонализацию отношений между всеми этими субъектами.

Выводы проведенного исследования значимы не только для понимания специфики политико-экономической и социальной организации региона ресурсного типа, но и для осознания общих закономерностей развития экономики и общества в современной России. Практики квазипубличного взаимодействия пронизывают и скрепляют всю сложившуюся в стране вертикаль власти.

\section{Литература}

Барсукова С.Ю. (2006) Сращивание теневой экономики и теневой политики // Мир России. T. 15. № 3. C. 158-179.

Барсукова С.Ю. (2011) Теневые правила взаимоотношений политиков и предпринимателей // Журнал институциональных исследований. Т. 3. № 3. С. 40-56.

Барсукова С.Ю., Левин С.Н. (2020) Соотношение административного и финансового ресурсов в ходе избирательных кампаний в современной России: региональная специфика // Мониторинг общественного мнения: Экономические и социальные перемены. № 4. С. 41-59.

Гельман В., Рыженков С. (ред.) (2000) Россия регионов: трансформация политических режимов. М.: Бри.

Дука А.В. (2019) Российские властные группы в (не)политическом пространстве. Вместо предисловия // Власть и элиты. Т. 6. № 1. С. 5-14.

Караяннис Э., Григорудис Э. (2016) Четырехзвенная спираль инноваций и «умная специализация»: производство знаний и национальная конкурентоспособность // Форсайт. T. 10. № 1. С. 31-42.

Клейнер Г.Б. (1996) Современная экономика России как «экономика физических лиц»// Вопросы экономики. № 4. С. 28-34.

Кранзеева Е.А., Бурмакина А.Л., Алтемерова О.А. (2020) Региональное социально-политическое взаимодействие: субъекты и репрезентанты // Вестник РГГУ. Серия: Философия. Социология. Искусствоведение. № 3. С. 76-86.

Кранзеева Е.А., Головацкий Е.В., Орлова А.В., Бурмакина А.Л. (2020) Смыслы жизни в оценках и ожиданиях жителей региона (результаты фокус-групп в Кемеровской области) // Социологические исследования. № 11. С. 58-67.

Кордонский С.Г. (2008) Сословная структура постсоветской России. М.: Институт Фонда «Общественное мнение».

Кордонский С.Г. (2010) Россия. Поместная Федерация. М.: Европа.

Левин С.Н. (2012) Политико-бюрократический рынок в современной России // Научные труды Донецкого национального технического университета. Серия: экономическая. № 41. C. 96-100.

Левин С.Н. (2014) Рынки власти, режимы прав собственности и политический ресурс предпринимателей в современной России // Мир России. Т. 23. № 4. C. 35-58.

Левин С.Н., Курбатова М.В. (2011) Сетевые взаимосвязи российского бизнеса: деловая коррупция и органический институт реальной модели институциональной организации российской экономики // Журнал институциональных исследований. Т. 3. № 2. C. 39-58.

Левин С.Н., Саблин К.С. (2018) Концепция рынков власти как методология исследования институциональной организации современной российской экономики и общества // Журнал институциональных исследований. Т. 10. № 4. С. 97-111.

Либман А. (2008) Направления и перспективы развития политико-экономических исследований // Вопросы экономики. № 1. С. 27-45. 
Олсон М. (2012) Власть и процветание: Перерастая коммунистические и капиталистические диктатуры. М.: Новое издательство.

Паппэ Я.Ш. (2002) Российский крупный бизнес как экономический феномен: специфические черты, модели его организации // Проблемы прогнозирования. № 2. С. 83-97.

Паппэ Я.Ш., Галухина Я.С. (2009) Российский крупный бизнес: первые 15 лет. Экономические хроники 1993-2008 гг. М.: ВШЭ.

Сакаева М.M. (2012) Парламент как «окно возможностей»: исследование поведения предпринимателей с депутатским мандатом в ходе реализации рыночных интересов // Экономическая социология. Т. 13. № 3. С. 96-122.

Чирикова А.Е., Ледяев В.Г. (2017) Власть в малом российском городе. М.: ВШЭ.

Шкаратан О.И. (2009) Становление постсоветского неоэтакратизма // Общественные науки и современность. № 1. С. 5-22.

Шкаратан О.И. (2011) Российская «псевдоэлита» и ее идентификация в мировом и национальном контекстах // Мир России. Т. 20. № 4. С. 68-88.

Шкаратан О.И., Ястребов Г.А. (2008) Российское неоэтакратическое общество и его стратификация // Социологические исследования. № 11. С. 40-50.

Штейнберг И.Е. (2014) Логические схемы обоснования выборки для качественных интервью: «восьмиоконная» модель // Социология: 4М. № 38. С. 38-71.

Barsukova S. (2019) Informal Practices of Big Business in the Postsoviet Period: From Oligarchs to "Kings of State Orders" // Demokratizatsiya: The Journal of Post-Soviet Democratization, vol. 27, no 1, pp. 31-50.

Carayannis E.G., Campbell D. (2014) Developed Democracies Versus Emerging Autocracies: Arts, Democracy, and Innovation in Quadruple Helix Innovation System // Journal of Innovation and Entrepreneurship, vol. 3, no 12, pp. 1-23.

Congleton R. (2019) The Political Economy of Rent Creation and Rent Extraction // The Oxford Handbook of Public Choice. Vol. 1. (eds. Congleton R., Grofman B., Voigt S.), Oxford: Oxford University Press, pp. 533-550.

Etzkowitz H. (1993) Technology Transfer: The Second Academic Revolution // Technology Access Report, no 6, pp. 7-9.

Etzkowitz H., Leydesdorff L. (1995) The Triple Helix - University-Industry-Government Relations: A Laboratory for Knowledge Based Economic Development // EASST Review, vol. 14, no 1, pp. 14-19.

Etzkowitz H., Zhou C. (2018) The Triple Helix: University-Industry-Government Innovation and Entrepreneurship, New York: Routledge.

Gel'man V. (2004) The Unrule of Law in the Making: The Politics of Informal Institution Building in Russia // Europe-Asia Studies, vol. 56, no 7, pp. 1021-1040.

Hirschman A.O. (1972) Exit, Voice, and Loyalty: Responses to Decline in Firms, Organizations, and States, Harvard: Harvard University Press.

Höglund L., Linton G. (2018) Smart Specialization in Regional Innovation Systems: A Quadruple Helix Perspective // R\&D Management, vol. 48, no 1, pp. 60-72.

Ledeneva A.V. (2006) How Russia Really Works: The Informal Practices That Shaped PostSoviet Politics and Business, Ithaca: Cornell University Press.

Persson T., Tabellini G. (2000) Political Economics. Explaining Economic Policy, Cambridge: MIT Press.

Stiglitz J. (2002) Globalization and Its Discontents, New York: W.W. Norton Company.

Torniainen T.J., Saastamoinen O.J. (2007) Formal and Informal Institutions and Their Hierarchy in the Regulation of the Forest Lease in Russia // Forestry, vol. 80, no 5, pp. 489-501.

Yakovlev A. (2006) The Evolution of Business-State Interaction in Russia: From State Capture to Business Capture? // Europe-Asia Studies, vol. 58, no 7, pp. 1033-1056. 


\title{
Stakeholders of Quasi-Public Interactions in a Resource-Abundant Region: an Insiders' Perspective
}

\author{
S. LEVIN*, E. KRANZEEVA**, K. SABLIN***
}

\begin{abstract}
*Sergey Levin - DSc in Economics, Professor, Department of Economic Theory and Public Administration, Kemerovo State University. Address: 6 Krasnaya St., Kemerovo, 650043, Russian Federation. E-mail: levin.sergey.n@gmail.com

**Elena Kranzeeva - PhD in Sociology, Associate Professor, Chair of Department of Sociological Sciences, Kemerovo State University. Address: 6 Krasnaya St., Kemerovo, 650043, Russian Federation. E-mail: elkranzeeva@mail.ru

$* * *$ Kirill Sablin $-\mathrm{PhD}$ in Economics, Associate Professor, Department of Economic Theory and Public Administration, Kemerovo State University. Address: 6 Krasnaya St., Kemerovo, 650043, Russian Federation. E-mail: sablin_ks@mail.ru
\end{abstract}

Citation: Levin S., Kranzeeva E., Sablin K. (2021) Stakeholders of Quasi-Public Interactions in a Resource-Abundant Region: an Insiders' Perspective. Mir Rossii, vol. 30, no 4, pp. 106-127 (in Russian). DOI: 10.17323/1811-038X-2021-30-4-106-127

\section{Abstract}

This article describes the stakeholders and practices of political and economic interaction in Kemerovo region as a resource-abundant region, based on in-depth interviews and a formalized survey. The stakeholders include higher regional officials and top managers of resource-extraction companies. The study provides an insider's perspective on a regional case, as the researchers themselves are deeply embedded in the social and economic realities of the Kemerovo region. This fact means that they were engaged in solving the problem of theorizing the commonness that is specific sociology. The solution this problem involves the use of a research strategy of grounded theory, which implies the choice of models and tools that correspond to the characteristics of the research object.

The chosen research methodology made it possible to describe the practices of quasi-public interaction that have in Kuzbass, which are characterized by the following features. Representatives of regional authorities and resource companies position themselves as subjects acting in the interests of the entire population of the region. At the same time, they monopolize the functions of formulating and realizing social development goals declaring that only they have the exclusive information and opportunities are necessary for this. Within the framework of this approach the population is practically excluded from the number of active subjects of political, economic and social interaction. Representatives of regional authorities and resource companies jointly implement both economic and political and administrative functions at the informal level. The incumbents involve entrepreneurs the implementation of political and administrative functions, including financing the production of public goods, various kinds of social and infrastructure projects, etc. Entrepreneurs agree to do these actions, because they realize that it is impossible to conduct any serious business without direct support from the authorities. All participants in political and economic interaction, i.e. political leaders, 
professional civil servants, owners and managers of resource companies behave not in accordance with their formal social roles, but as persons included in a closed vertical social network.

Keywords: resource-abundant region; quasi-public interaction; personalization; authorities; resource-extraction companies; population; in-depth interview

\section{References}

Barsukova S.Yu. (2006) Srashchivanie tenevoy ekonomiki i tenevoy politiki [Coalescence of Shadow Economy and Shadow Policy]. Mir Rossii, vol. 15, no 3, pp. 158-179.

Barsukova S.Yu. (2011) Tenevye pravila vzaimootnosheniy politikov i predprinimateley [Shadow Rules of Relations between Politicians and Entrepreneurs]. Journal of Institutional Studies, vol. 3, no 3, pp. 40-56.

Barsukova S. (2019) Informal Practices of Big Business in the Post-soviet Period: From Oligarchs to "Kings of State Orders". Demokratizatsiya: The Journal of Post-Soviet Democratization, vol. 27, no 1, pp. 31-50.

Barsukova S.Yu., Levin S.N. (2020) Sootnoshenie administrativnogo i finansovogo resursov v khode izbiratel'nykh kampaniy $\mathrm{v}$ sovremennoy Rossii: regional'naya spetsifika [The Ratio of Administrative and Financial Resources during Election Campaigns in Modern Russia: Regional Specifics]. Monitoring obshchestvennogo mneniya: Ekonomicheskie $i$ sotsial'nye peremeny, no 4, pp. 41-59.

Carayannis E.G., Campbell D. (2014) Developed Democracies Versus Emerging Autocracies: Arts, Democracy, and Innovation in Quadruple Helix Innovation System. Journal of Innovation and Entrepreneurship, vol. 3, no 12, pp. 1-23.

Chirikova A.Y., Ledyaev V.G. (2017) Vlast'v malom rossiyskom gorode [Power in a Small Russian Town], Moscow: HSE.

Congleton R. (2019) The Political Economy of Rent Creation and Rent Extraction. The Oxford Handbook of Public Choice.Vol. 1 (eds. Congleton R., Grofman B., Voigt S.), Oxford: Oxford University Press, pp. 533-550.

Duka A.V. (2019) Rossiyskie vlastnyye gruppy v (ne)politicheskom prostranstve. Vmesto predisloviya [Russian Power Groups in (Non)political Space. Instead of a Preface]. Vlast'ielity, vol. 6 , no 1 , pp. 5-14.

Etzkowitz H. (1993) Technology Transfer: the Second Academic Revolution. Technology Access Report, no 6, pp. 7-9.

Etzkowitz H., Leydesdorff L. (1995) The Triple Helix - University-Industry-Government Relations: A Laboratory for Knowledge Based Economic Development. EASST Review, vol. 14, no 1, pp. 14-19.

Etzkowitz H., Zhou C. (2018) The Triple Helix: University-Industry-Government Innovation and Entrepreneurship, New York: Routledge.

Gel'man V. (2004) TheUnrule of Law in the Making: The Politics of Informal Institution Building in Russia. Europe-Asia Studies, vol. 56, no 7, pp. 1021-1040.

Gel'man V., Ryzhenkov S. (eds.) (2000) Rossiya regionov: transformatsiya politicheskikh rezhimov [Russia of Regions: Transformation of Political Regimes], Moscow: Bri.

Hirschman A.O. (1972) Exit, Voice, and Loyalty: Responses to Decline in Firms, Organizations, and States, Harvard: Harvard University Press.

Höglund L., Linton G. (2018) Smart Specialization in Regional Innovation Systems: A Quadruple Helix Perspective. R\&D Management, vol. 48, no 1, pp. 60-72.

Karayannis E., Grigorudis E. (2016) Chetyrekhzvennaya spiral' innovatsiyi «umnayaspetsializatsiya»: proizvodstvo znaniy I natsional'naya konkurentosposobnost' 
[The Quadruple Helix of Innovation and "Smart Specialization": Knowledge Production and National Competitiveness]. Foresight and STI Governance, vol. 10, no 1, pp. 31-42.

Kleyner G.B. (1996) Sovremennaya ekonomika Rossii kak «ekonomika fizicheskikh lits» [The Modern Economy of Russia as the "Economy of Individuals"]. Voprosy ekonomiki, no 4, pp. 28-34.

Kordonsky S.G. (2008) Soslovnaya struktura postsovetskoy Rossii [Estate Structure of Post-Soviet Russia], Moscow: Institute of Foundation «Obshchestvennoemnenie».

Kordonsky S.G. (2010) Rossiya. Pomestnaya Federatsiya [Russia: Estate Federation], Moscow: Evropa.

Kranzeeva E.A., Burmakina A.L., Altemerova O.A. (2020) Regional'noye sotsial'nopoliticheskoye vzaimodeystviye: subyekty Ii reprezentanty [Regional Socio-political Interaction: Subjects and Representatives]. Vestnik RGGU. Seriya: Filosofiya. Sotsiologiya. Iskusstvovedenie, no 3, pp. 76-86.

Kranzeeva E.A., GolovatskiyYe.V., Orlova A.V., Burmakina A.L. (2020) Smyslyzhizni $\mathrm{v}$ otsenkakh i ozhidaniyakh zhiteley regiona (rezul'taty fokus-grupp v Kemerovskoy oblasti) [Meanings of Life in the Assessments and Expectations of Residents of the Region (Results of the Focus Groups in the Kemerovo Region)]. Sotsiologicheskie issledovaniya, no 11, pp. 58-67.

Ledeneva A.V. (2006) How Russia Really Works: The Informal Practices That Shaped Post-Soviet Politics and Business, Ithaca: Cornell University Press.

Levin S.N. (2012) Politiko-byurokraticheskiy rynok v sovremennoy Rossii [Political and Bureaucratic Market in Modern Russia]. Nauchnye Trudy Donetskogo natsional'nogo tekhnicheskogo universiteta. Seriya: ekonomicheskaya, no 41, pp. 96-100.

Levin S.N. (2014) Rynki vlasti, rezhimy prav sobstvennosti i politicheskiy resurs predprinimateley v sovremennoy Rossii [Markets of Power, Regimes of Property Rights and the Political Resource of Entrepreneurs in Modern Russia]. Mir Rossii, vol. 23, no 4, pp. 35-58.

Levin S.N., Kurbatova M.V. (2011) Setevye vzaimosvyazi rossiyskogo biznesa: delovaya korruptsiya I organicheskiy institute real'noy modeli institutsional'noy organizatsii rossiyskoy ekonomiki [Network Interconnections of Russian Business: Business Corruption and the Organic Institution of the Real Model of the Institutional Organization of the Russian Economy]. Journal of Institutional Studies, vol. 3, no 2, pp. 39-58.

Levin S.N., Sablin K.S. (2018) Kontseptsiya rynkov vlasti kak metodologiya issledovaniya institutsional'noy organizatsii sovremennoy rossiyskoy ekonomiki i obshchestva [The Concept of Power Markets as a Methodology for Studying the Institutional Organization of the Modern Russian Economy and Society]. Journal of Institutional Studies, vol. 10, no 4, pp. 97-111.

Libman A. (2008) Napravleniya i perspektivy razvitiya politiko-ekonomicheskikh issledovaniy [Directions and Prospects for the Development of Political and Economic Studies]. Voprosy ekonomiki, no 1, pp. 27-45.

Olson M. (2012) Vlast' $i$ protsvetaniye: Pererastaya kommunisticheskiye $i$ kapitalisticheskiye diktatury [Power and Prosperity: Outgrowing Communist and Capitalist Dictatorships], Moscow: Novoeizdatel'stvo.

PappeYa.Sh. (2002) Rossiyskiy krupnyy biznes kak ekonomicheskiy fenomen: spetsificheskiye cherty, modeli yego organizatsii [Russian Big Business as an Economic Phenomenon: Specific Features, Models of Its Organization]. Problemy prognozirovaniya, no 2, pp. 83-97.

PappeYa.Sh., GalukhinaYa.S. (2009) Rossiyskiy krupnyy biznes: pervyye 15 let. Ekonomicheskie khroniki 1993-2008 [Russian Big Business: The First 15 Years. Economic Chronicles 1993-2008], Moscow: HSE.

Persson T., Tabellini G. (2000) Political Economics. Explaining Economic Policy, Cambridge: MIT Press.

Sakaeva M.M. (2012) Parlament kak «oknovozmozhnostej»: issledovanie povedeniya predprinimatelej $\mathrm{s}$ deputatskim mandatom $\mathrm{v}$ hode realizacii rynochnyh interesov [Parliament as a "Window of Opportunity": A Study of the Behavior of Entrepreneurs with a Parliamentary Mandate in the Course of Realizing Market Interests]. Journal of Economic Sociology. vol. 13, no 3, pp. 96-122. 
Shkaratan O.I. (2009) Stanovleniye postsovetskogo neoetakratizma [Formation of post-Soviet Neoetacratism]. Obshchestvennye nauki i sovremennost', no 1, pp. 5-22.

Shkaratan O.I. (2011) Rossiyskaya «psevdoelita» i yeye identifikatsiya v mirovom i natsional'nom kontekstakh [Russian "Pseudo-elite" and Its Identification in the Global and National Contexts]. MirRossii, vol. 20, no 4, pp. 68-88.

Shkaratan O.I., Yastrebov G.A. (2008) Rossiyskoye neoetakraticheskoye obshchestvoi ego stratifikatsiya [Russian Neoetacratic Society and Its Stratification]. Sotsiologicheskie issledovaniya, no 11, pp. 40-50.

Shteynberg I.Ye. (2014) Logicheskiye skhemy obosnovaniya vyborki dlya kachestvennykh interv'yu: «vos'miokonnaya» model' [Logical Schemes for Substantiating the Sample for Qualitative Interviews: The "Eight-Window" Model]. Sotsiologiya: 4M, no 38, pp. 38-71.

Stiglitz J. (2002) Globalization and Its Discontents, New York: W.W. Norton Company.

Torniainen T.J., Saastamoinen O.J. (2007) Formal and Informal Institutions and Their Hierarchy in the Regulation of the Forest Lease in Russia. Forestry, vol. 80, no 5, pp. 489-501.

Yakovlev A. (2006) The Evolution of Business-State Interaction in Russia: From State Capture to Business Capture? Europe-Asia Studies, vol. 58, no 7, pp. 1033-1056. 